\title{
El Instituto Nacional de Salud y la Epidemia de Cólera
}

\author{
The National Institute of Health and the epidemic of Cholera
}

\section{CARRILLO Carlos ${ }^{1}$}

\section{INTRODUCCIÓN}

La epidemia de cólera en el Perú aparece casi simultáneamente en varias ciudades de la costa a fines de enero de 1991. Aunque la fuente de origen permanece oscura, la rápida diseminación a varias ciudades costeras lejanas entre si, sugiere un vehículo de transmisión a través de la distribución y expendio de alimentos sin las condiciones de higiene recomendadas por las autoridades de Salud (1). Desde entonces, una intensa y sostenida diseminación ha ocurrido en varias ciudades afectando sobre todo a la población económicamente deprimida. La enfermedad se expande a fines de febrero a la sierra andina, y a fines de marzo a la selva así como a países limítrofes tales como Ecuador, Colombia, Brasil y Chile.

El Ministerio de Salud del Perú, ha reportado 316,299 casos sospechosos de cólera, 87,659 hospitalizaciones y 2,193 defunciones, con una letalidad de $0.97 \%$ hasta el 1 de julio de 1991.

La curva epidemiológica de 25 semanas de la epidemia de cólera del Perú, demuestra una clara disminución en el número de casos probables de cólera así como de las hospitalizaciones por la enfermedad.

Según la Resolución Ministerial $\mathrm{N}^{\mathrm{o}}$ 0158-91-SA/DM, el INS forma parte de la Comisión Ejecutiva Nacional para el control del Cólera. Esta comisión está presidida por el Ministro de Salud e integrada por el Vice-Ministro, el Director del Instituto Nacional de Salud y la Dirección General de Atención a las Personas.

\section{LINEAMIENTOS DE POLITICA INSTITUCIONAL}

Red Nacional de Laboratorios de Lima

Para atender la demanda de la confirmación bacteriológica de los casos clínicos de cólera, el Instituto Nacional de Salud implementó rápidamente la Red de Emergencia de Laboratorios de Cólera. La organización forma parte de la gestión de recuperación institucional que se efectúa a partir de octubre de 1990. Este proceso de recuperación, comprende entre sus siete lineamientos de política, el de la creación de la Red Nacional de Laboratorios de Salud de Piura, Ica, Huancayo, Cuzco y Arequipa. A fines de 1990, ya se estaban incorporando los de Tingo María, Pucallpa y Tacna, como extensión del Programa del Control del Sida. En la actualidad comprende las siguientes ciudades: Tumbes, Piura, Trujillo, Chimbote, Cajamarca, Jaén, Iquitos, Tarapoto, Huaraz, Tingo María, Huánuco, Pucallpa, Tarma, Huancayo, Ica, Huancavelica, Ayacucho, Cuzco, 
Puerto Maldonado, Puno, Arequipa, Tacna. El departamento de Lima incluye: Hospital Hipólito Unanue, Hospital Dos de Mayo, Hospital Maternidad de Lima, Hospital María Auxiliadora, Hospital Cayetano Heredia, Hospital Arzobispo Loayza, Hospital Santa Rosa, Hospital de Emergencias Casimiro Ulloa, Hospital de Emergencias Pediátricas, Hospital Daniel A. Carrión, Instituto Nacional de Salud del Niño, Hospital de Chancay, Instituto Materno Infantil San Bartolomé, Hospital Materno Infantil M. Barreto, Hospital San José Villa El Salvador, Instituto Nacional de Enfermedades Neoplásicas, Laboratorio de la Dirección General de Saneamiento Ambiental, Laboratorio de Microbiología del Instituto Nacional de Nutrición.

Esta actividad incluye también a los miembros de la Oficina General de Epidemiología del Ministerio de Salud. Esta renovación institucional explica la rápida y eficaz presencia del Instituto Nacional de Salud en ésta epidemia de cólera.

Por primera vez en el presente siglo aparece el cólera simultáneamente en varias ciudades del litoral del Perú. La última epidemia de cólera en Latinoamérica, fue en Chile en el año 1863, causando aproximadamente 28,000 muertes. Esta introducción multifocal de origen desconocido, sugiere que sean varios los vehículos específicos tales como alimentos de diferentes clases y de agua contaminada. Su similitud con la epidemia de cólera en Italia en 1973, coincide en su aparición estacional y de consumo de pescado y mariscos crudos, relación climático/alimenticia que se manifiesta en áreas endémicas (2,3). En Japón, donde el pescado y otros alimentos del mar se consumen crudos, el V. parahemoliticus es una de las causas más comunes de gastroenteritis. La persistencia y transmisión están delimitadas por condiciones ambientales climáticas y prácticas sanitarias.

\section{B.Etiología y Mecanismos de Transmisión}

El cólera es causado por el Vibrio cholerae-01, que se divide en dos biotipos, Clásico y El Tor, diferenciándose en cuanto a su actividad hemolítica, susceptibilidad al bacteriófago y a la Polimixina B (4).

A partir de la séptima pandemia (1961) los Vibrio cholerea 01, del grupo Clásico han sido reemplazados por cepas bacterianas del grupo El Tor. Una de las razones para este cambio, se explica por la mayor habilidad que posee este último grupo, para sobrevivir fuera del huésped (5). El germen puede permanecer en el ambiente acuático durante un año, lo que le permite su permanencia no sólo en la epidemia, sino en las formas endémicas e inter epidémicas.

En este ambiente acuático, la bacteria se adhiere frecuentemente a otros organismos residentes, apareciendo invisibles a los métodos tradicionales de detección de bacterias patógenas. Está demostrada la producción de la enzima chititas, que actúa sobre la quitina de los copépodos (zooplankton) y del Volvox (phytoplankton); la capa de quitin proteje al V.cholerae de la acción de la acidez gástrica $(6,7)$.

El mecanismo de transmisión es por vía fecal/oral, siguiendo el mismo esquema que en otras enfermedades diarreicas: heces-manos-alimentos/bebidas-boca. Al ser eliminado por las heces, el Vibrio cholerae se encuentra en las aguas de desagüe o en cualquier otra forma de contaminación fecal directa o indirecta. Lo que se detecta también con la presencia de bacterias coliformes e indicador de coli-fecal, tanto en el medio ambiente 
así como de los alimentos que de alguna forma son manipulados durante la epidemia (cuadro $\mathrm{N}^{\circ} 1$ ). De 237 productos del mar analizados, el 3.8\% mostró contaminación para V. cholerae sea en intestino o piel-agallas. El 100\% de ellos exhibe contaminación por indicador fecal.

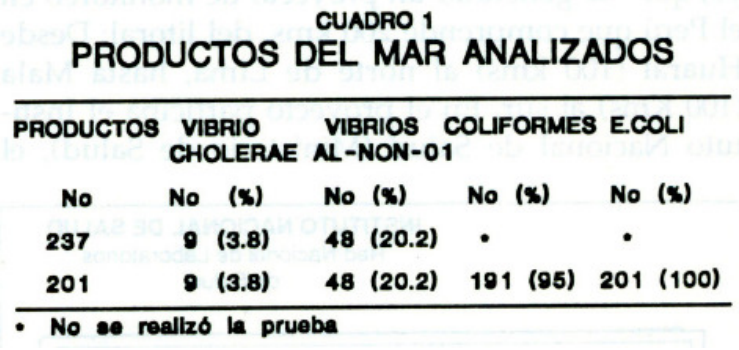

Las manifestaciones clínicas siguen los patrones de las enfermedades diarreicas, cuyos síntomas principales son diarrea y vómito, habiendo una proporción de población infectada (1:50) que puede tener sintomatología clásica y otra que presenta formas moderadas, leves o asintomáticas.

Iniciada la epidemia y efectuado el diagnóstico del Vibio cholerae-01 por el Instituto Nacional de Salud del Perú, se establece la Red de Laboratorios de Emergencia de Cólera. Las cuatro primeras cepas V. cholerae en el Perú, identificadas como Vibrio cholerae 01, El Tor (toxigénico) correspondían a las ciudades de Chancay y Chimbote. Hasta el 1 de julio de 1991 se han capacitado 87 profesionales (médicos, biólogos, técnicos y auxiliares) en los 69 establecimientos de salud donde se efectúa el diagnóstico en humanos y en alimentos, bebidas y aguas superficiales.

El Vibrio cholerae-01 El Tor, puede permanecer en el ambiente acuático por tiempo prolongado sin reproducirse. Por ello el microorganismo es viable no sólo durante las epidemias sino en épocas inter-epidémicas o pre-epidémicas (8). En el Laboratorio de Microbiología Ambiental del Instituto Nacional de Salud para investigar la existencia de reservorios acuáticos en el Continente y en el área del litoral nacional se está empleando anticuerpos monoclonales por fluoresceína (antígeno A de V. cholerae-01, lipopolisacárido) (8,9). Ello permite establecer una Área Piloto de estudio y de aplicación, comparando esta tecnología con los procedimientos clásicos.

Las aguas contaminadas con desechos humanos, son fuente importante en la diseminación del V. cholerae. Los colectores de desagüe que las ciudades arrojan al mar son fuente de contaminación cuando contienen dichos agentes. Igualmente se contaminan los productos de tallo corto que son regadas con aguas de desagües en la región continental. Este vehículo contribuye también a la propagación de la enfermedad.

En la figura $\mathrm{N}^{\circ} 1$ se ilustra el Área Piloto de ensayo, que ha generado un proyecto de monitoreo en el Perú que comprende 200 kms., del litoral: desde Huaral (100 kms) al norte de Lima, hasta Mala (100 kms.) al sur. En el proyecto participa el Instituto Nacional de Salud (Ministerio de Salud), el Instituto del Mar del Perú, (Ministerio de Pesquería) y CEPIS (OPS/OMS). Se está comparando la tecnología tradicional con la tecnología rápida en áreas paralelas y que corresponden a ciudades del continente y puertos. Este estudio comprende: alimentos, aguas superficiales, líneas de distribución de agua potable, áreas agrícolas irrigadas con aguas servidas, aguas del mar y sus 
recursos hidrobiológicos. Los resultados de estos estudios permitirán las evaluaciones respectivas para la aplicación en otras áreas que requieren ser clasificadas.

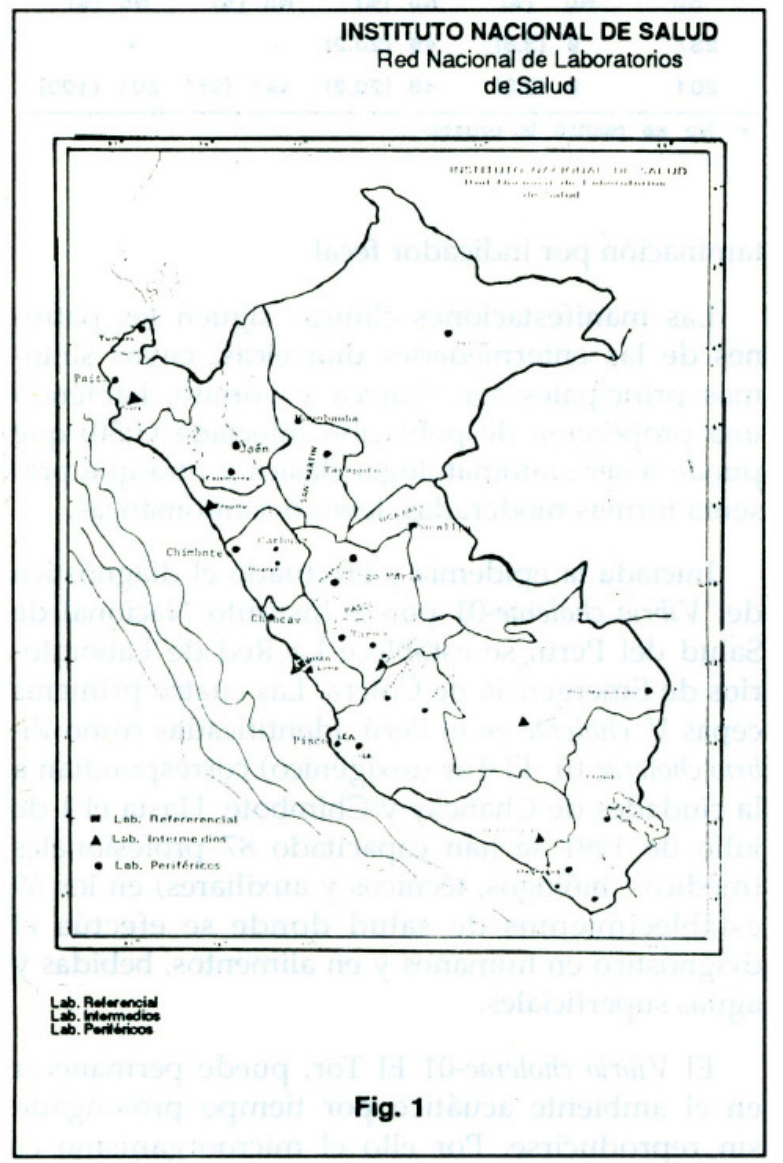

En el Perú, los factores de transmisión son de causa polifactorial por las condiciones de deterioro de la infraestructura sanitaria, por la provisión de aguas potables por los mecanismos de descarte de aguas servidas y de las excretas humanas. Los moluscos bivalvos, (choros) que crecen en las peñas del litoral se contaminan en zonas próximas a los colectores de aguas servidas. Otro factor, de propagación de la enfermedad es la transmisión alimentaria, que está vinculada directamente con los hábitos alimentarios/ higiénicos y la situación socio-económica de cada población.

Utilizando el método de anticuerpos fluorescentes descrito, en el colector del sur de Lima, (Sur La Chira) se ha demostrado la presencia cuantitativa de 430,000 Vibrio cholerae-01 por $100 \mathrm{ml}$., de agua. No solo infecta el agua de mar frente al colector, sino también las verduras de tallo corto que se irrigan con el agua de dicho colector. También se puede contaminar algunas especies marinas costeras, tanto en el intestino, como piel-agallas de pescado. Además la contaminación en época de epidemia por el manipuleo, evisceramiento y lavado con aguas infectadas por Vibrio cholerae y otras enterobacterias. Este hallazgo ocurre en época epidémica en $3.8 \%$ de los pescados y mariscos examinados en la 2da. Quincena del mes de marzo, cuando inicia sus actividades el Laboratorio de Microbiología Ambiental. El segundo monitoreo realizado en la primera quincena del mes de mayo muestra que ningún producto del mar está contaminado por V. cholerae-01. Los alimentos comerciales por venta ambulatoria también sufren este mismo proceso de contaminación cuando no se cumple durante su 
preparación las mínimas reglas de higiene. Por ello el muestreo de estos alimentos de preparación y expendio ambulatorio muestran contaminación por el Vibrio cholerae (RIMSA) 7/22:30 de abril, 1991). La contaminación de los utensilios utilizados (platos y tablas de picar), fluctúa entre $9.1 \%$ (platos) y $66.7 \%$ (tablas de picar).

El Laboratorio de Microbiología Ambiental está realizando, estudios de detección del V. cholerae-01 en los desagües que desembocan desde la ciudad de Puno al Lago Titicaca (figura 2), así como en el agua del mismo lago. En 10 colectores analizados se ha hallado la presencia de V. cholerae-01, en 6 de ellos.

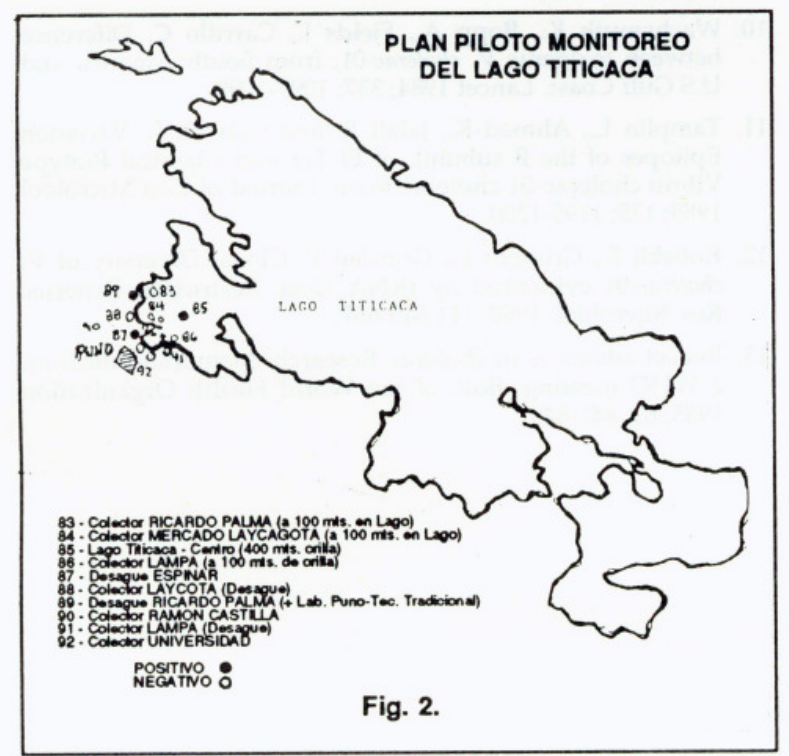

En 10 colectores de aguas servidas en la ciudad de Iquitos que desemboca en el Rió Amazonas (figura 3), 4 de ellos están contaminados con V.cholerae-01. Los peces de ambos estudios no han mostrado contaminación específica a esta bacteria.

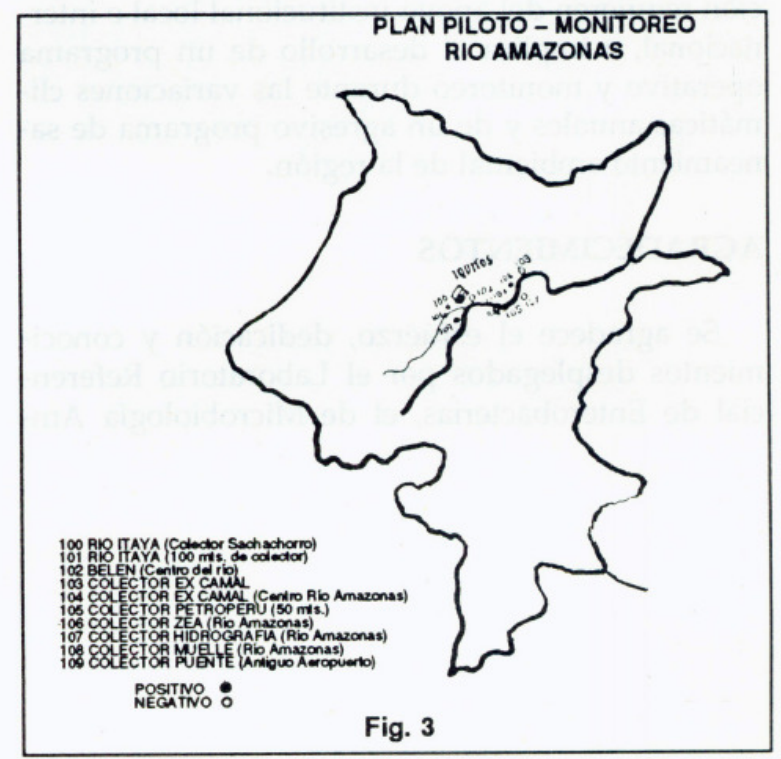

INVESTIGACIONES REALIZADAS 
Las razones expuestas, motivaron la creación de un Laboratorio de Microbiología Ambiental en marzo de 1991, con la colaboración de la Universidad de Florida y el auspicio de la OPS/OMS. University of Florida, IFAS, Food Safety Unit.

Los estudios demuestran la resistencia del V. cholerae-01 (cepa aislada en el Perú) a los factores ambientales.

La susceptibilidad antibiótica de la cepa V. cholerae-01 frente a ocho diferentes antibióticos por el método de mínima concentración inhibitoria (MIC), muestra una susceptibilidad a la tetraciclina.

En lo que respecta a la resistencia del V. cholerae-01, aislado en el Perú, a factores ambientales (fenotípicos), es necesario remarcar que producen mutantes no móviles espontáneos a alta frecuencia $\left(10^{-4}\right)$, las cepas de V. cholerae El Tor, no producen mutantes.

La cepa de V. cholerae-01 aislado en el país, no es hemolítica, es negativa para el vibriófago Vc A-3 y contiene el gene de toxina colérica (LT) en un fragmento simple de $9.5 \mathrm{~kb}$.

Estudios de caracterización molecular, en ejecución en colaboración con el Centro de Enfermedades Transmisibles (CDC) de Atlanta, USA, demuestran que el V.cholerae, de la epidemia de Sud América, en 1991 es toxigénico, serotipo Inaba, biotió El Tor. Este germen es genotípica y genotípicamente similar a las cepas de séptima pandemia provenientes de Asia y África y diferentes a las bacterias V. cholerae-01, aislados de la costa del Golfo de México en 1973 (10,11).

Además de han efectuado las pruebas fenotípicas, extracción del DNA cromosomial y analizados por ensayos de Southern Blot. Se han producido sondas para los genes de la toxina colérica (LT) y para los genes rRNA16S y Rrna 23S (12). Los Ribotipos indican que las cepas de V.cholerae-01, Sudamericana, es similar a las Islas Malawi (1990), Truk (1990), Thailanda (1990), Philippines (1987).

Todos los estudios mencionados siguen continuamente renovándose, incluyendo la aparición del serotipo Ogawa, la que por técnicas de hibridización rRNA e isoenzimas parece ser la misma que las cepas Inaba anteriores (13). Tal como se aprecia en dicha figura, esta variedad serológica aparece en el Perú, desde el 15 de mayo de 1991.

Estas variaciones serológicas, son de aparición espontánea y se producen al término de la curva epidémica del cólera, pudiendo ser en ambos sentidos (Ogawa.Inaba); InabaOgawa) y sin poseer expresión antigénica (13).

\section{BASE DE DATOS}

El Departamento de Epidemiología del Centro de Referencia de Laboratorios de Salud Pública del INS, almacena esta información en los programas EPI-INFO, LOTUS 123, DBASE, y los procesadores de texto WORDPERFECT, WORD Y FLOW. 


\section{ACTIVIDAD INTERNACIONAL}

Eventos importantes se están programando en las siguientes fechas: El primer Curso Internacional de Laboratorio en Investigación de V. cholerae del 8 al 13 de julio, 1991; la primera Reunión de Expertos Latinoaméricanos en Cólera, del 15 al 17 de julio, 1991, la primera Reunión de Directores de Institutos Nacionales de Salud de Latinoamérica, del 18 al 20 de julio, 1991. Las conclusiones y recomendaciones de estos eventos serán muy importantes para consolidar los sentimientos de solidaridad e integración Latinoamericana en ciencia y tecnología.

\section{CONCLUSIONES}

Los datos presentados indican la naturaleza polifactorial en la transmisión del cólera en Perú: agua, alimentos, enfermos, personas aparentemente sanas que son excretores de Vibrio cholerae. Esto significa la necesidad urgente de implantar sistemas de vigilancia con tecnología moderna, adecuada y rápida para alimentos, distribuidores de agua, calidad de aguas para el lavado, elaboración y manipulación de alimentos y riego de verduras, así como de las aguas de mar para prevenir su contaminación. También la necesidad de tender una red de laboratorios que establezcan las áreas de riesgo de contaminación fecal y su vigilancia, tanto de las aguas superficiales del continente y sus productos, como de los correspondientes del litoral y sus recursos. Estos esfuerzos de investigación requieren del apoyo institucional local e internacional, e implica el desarrollo de un programa operativo y monitoreo durante las variaciones climáticas anuales y de un agresivo programa de saneamiento ambiental de la región.

\section{AGRADECIMIENTOS}

Se agradece el esfuerzo, dedicación y conocimientos desplegados por el Laboratorio Referencial de Enterobacterias, el de Microbiología Ambiental, así como a los miembros integrantes del Subcomité de Lucha contra el cólera del INS, constituido en virtud de la RM 140-91.

A la Oficina Panamericana de Salud en Lima, que apoya la estructura de la Red Nacional de Laboratorios.

A la Embajada de Japón a través de la JICA, que ha donado medios de cultivo y antisueros que se distribuyen en todos los puntos donde se encuentran laboratorios del Sector Salud.

A todo el personal del INS que participa en el seguimiento del programa del control del cólera.

\section{REFERENCIAS BIBLIOGRÁFICAS}

Vidal C, Carrillo C., Seminario L. Cholerae Perú 1991 MMWR (CDC) 1991, 40: 108110.

BaineB., Zampieri J. Epidemiology of cholera in Italy in 1973. Lancet 1974; 1370. 
Gangarose J. Mosley H., Cholera (edited by D. Barua and W. Burrows) Philadelphia, 1974: 390.

Blake A., Wachsmuth K., Davis R. Toxigenic Vibrio cholerae 01 strains from Mexico identical to United States isolates. Lancet, 1983: 912.

Kaper B., Bradford B., Roberts C., Falkow S. Molecular Epidemiology of V. cholerae in U.S. Gulf Coast. J. Clinical Microb 1982; 16: 129-134.

Aquatic niche is haven for Vibrio cholera, ASM News 1989; 55 (12): 642.

Tamplin L., Gauzens L, Huk A., Sack A. and Colwelll R. Attachment of Vibrio cholerae Serogroup 01 to Zooplankton and phytoplankton of Blangladesh waters. Appl. Environ. Microbiology 1990; 56: 1977-1980.

Brayton R., Tamplin L., Huk A. and Colwell R. Enumeration of Vibrio cholerae-01 in Blangledesh waters by Fluorenscent -antibody direct viable count. Appl. Environ. Microbiology 1987; 53: 2862-2865.

Wachsmuth K., Bopp A., Fields I., Wells G., Carrillo C. and Blake A., Characteristics of ToxigenicV. Cholerae -01 Strains isolated from Epidemic cholerae in South America in 1991. Abstract submitted to the U.S. Japan Cholera Panel September 1990.

Wachsmuth K., Bopp A., Fields I., Carrillo C. Diference between toxigenic V. cholerae 01, from South America and U.S Gulf Coast. Lancet 1984; 337: 1097-1098.

Tamplin L, Ahmed K., Jalali R. and Colwell R. Variation Epitopes of the B subunit of El Tor and Classical Biotype Vibrio cholerae-01cholerae toxin. Journal of Gen Microbiol 1989; 135: 1195-1200.

Kobabli S., Grimont F., Grimont P. Clonal Diversity of V. cholerae-01 evidenced by rRna Gene Restriction Patterns. Res. Microbiol. 1990; 141:645-657.

Rencet advances in cholerae Research: Memorandum from a WHO meeting Bull. Of the World Health Organization 1985; 63: 841-849. 